\title{
Geometric Synthesis of Involute Planetary Gears with Connected Gear Wheels of Type $2 \mathrm{~K}-\mathrm{H}$
}

\author{
Genadi Cvetanov \\ Department of Mechanical and Precision Engineering \\ Technical University of Gabrovo \\ Gabrovo, Bulgaria \\ gencvet@tugab.bg
}

\author{
Tsanko Karadzhov \\ Department of Mechanical and Precision Engineering \\ Technical University of Gabrovo \\ Gabrovo, Bulgaria \\ karadjov_st@abv.bg
}

\begin{abstract}
Based on the basic law of flat interlocking, the paper considers a possibility of increasing the gear ratio of low module involute cylindrical planetary gears by using asymmetric tooth profile for the purposes of measuring devices. An example of the synthesis of such reduction gearing by optimal choice of asymmetry between the profiles and Possibility of generation III is presented. Also presented is a planar matching of the unconditional existence areas in the field of independent coefficients of instrument displacement by the straight optimization method and preset qualitative indicators of the gearing.
\end{abstract}

Keywords - planetary involute cylindrical tooth gears, asymmetric profile

\section{INTRODUCTION}

With large gear ratios in precision engineering gears with combined gearing - internal and external are used. These are the epicyclical gear drives, of which the most widely spread is the kinematic scheme of $2 \mathrm{~K}-\mathrm{H}$ involute cylindrical gear with symmetrical tooth profile and different number of steps [1] [2] [3].

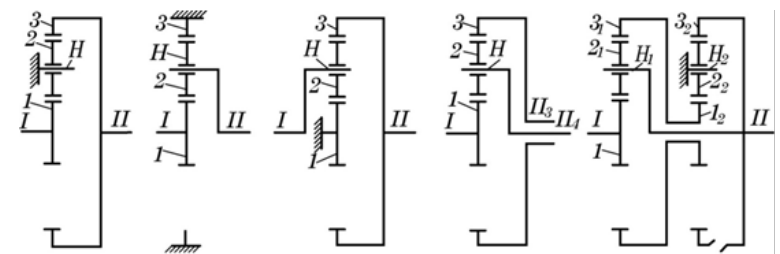

Fig. 1. Kinematic schemes of variants of gear $2 \mathrm{~K}-\mathrm{H}$

According to fig. 1, five basic kinematic schemes of an epicyclical mechanism with geometrically connected gears are possible. Gear axes 1 and 3 coincide with the mutual geometric axis and are called basic units of the mechanism and the corresponding gears are called central. The gear

ratio is the ratio of the angular velocities of the two units 1 and 3. Gear 2 engaged with units 1 and 3 does not affect the gear ratio from shaft I to shaft II and is called a satellite wheel.

The carrier that carries the satellites can serve as the main unit and in fig. 1 it is denoted by the letter $\mathrm{H}$. In this case the axis of gear 2 moves in space and the gear is called planetary. Gear mechanism in which at least one axis is mobile in space is called a planetary gear mechanism.

When the epicyclical gear mechanism has two degrees of freedom it is called "differential”, and with one degree of freedom - "planetary". Combination of internal and external gearing in one gear mechanism has a number of advantages, some of which are:

- $\quad$ expanding the possibilities of planar gearing by possible choice of three coefficients of displacement and heights of the tooth profiles;

- $\quad$ increased load capacity of the gear at high torque;

- $\quad$ obtaining gears with larger gearing angles and higher frontal overlap coefficient than those realized only with external gearing at the same gear ratio;

- compactness of construction and manufacturability in the process of manufacturing the gear wheels.

\section{EXPOSITION}

Depending on the specific implementation $2 \mathrm{~K}-\mathrm{H}$ uniaxial gears can be with or without connected wheels [4] [5]:

$$
\mathrm{m}_{\mathrm{t}_{1,2}}=\frac{\mathrm{z}_{2} \pm \mathrm{z}_{1}}{\cos \alpha_{\mathrm{tw}_{12}}}=\mathrm{m}_{\mathrm{t}_{3,4}}=\frac{\mathrm{z}_{4} \pm \mathrm{z}_{3}}{\cos \alpha_{\mathrm{tw}_{34}}}
$$


$\mathrm{m}^{*} \mathrm{t}_{1,2}=\frac{\mathrm{z}_{2} \pm \mathrm{z}_{1}}{\cos \alpha_{\mathrm{tw}_{12}}^{*}}=\mathrm{m}^{*}{ }_{\mathrm{t}_{3,4}}=\frac{\mathrm{z}_{4} \pm \mathrm{z}_{3}}{\cos \alpha_{\mathrm{tw}_{34}}^{*}}$

where $\mathrm{m}_{\mathrm{t} 1,2}$ and $\mathrm{m}_{\mathrm{t} 3,4}$ are the front modules of the coupled gears;

$\mathrm{z}_{1}, \mathrm{z}_{2}, \mathrm{z}_{3}$ and $\mathrm{z}_{4}$ - the number of teeth of the gear wheels;

$\alpha_{\mathrm{tw} 1,2}$ and $\alpha_{\mathrm{tw} 3,4}$ - engagement angles between the coupled gear wheels for the "working part" of the tooth profile;

$\alpha^{*}{ }_{t w 1,2}$ and $\alpha^{*}{ }_{t w 3,4}$ - engagement angles between the coupled gear wheels for the "non-working part" of the tooth profile;

In case of an asymmetric tooth profile the engagement angles are determined depending on the type of formation and the following transcendental dependencies:

$$
\begin{aligned}
& i n v \alpha_{t w_{1,2}}+i n v \alpha_{t w_{1,2}}^{*}=\frac{2 \cdot\left(x_{2} \pm x_{1}\right) \cdot\left(\operatorname{tg} \alpha+\operatorname{tg} \alpha^{*}\right)}{z_{2} \pm z_{1}}+ \\
& \frac{d_{t b_{1,2}}}{\cos \alpha_{t w_{1,2}}}=\frac{d_{t b_{1,2}}^{*}}{\cos \alpha_{t w_{1,2}}^{*}} \\
& i n v \alpha_{t w_{3,4}}+i n v \alpha_{t w_{3,4}}^{*}=\frac{2 \cdot\left(x_{4} \pm x_{3}\right) \cdot\left(\operatorname{tg} \alpha+\operatorname{tg} \alpha^{*}\right)}{z_{4} \pm z_{3}}+ \\
& \frac{d_{t b_{3,4}}}{\cos \alpha_{t w_{3,4}}}=\frac{d_{t b_{3,4}}^{*}}{\cos \alpha_{t w_{3,4}}^{*}}
\end{aligned}
$$

where $d_{t b 1,2}$ and $d_{t b 3,4}$ are the diameters of the main circles in the frontal section for the "working part" of the tooth profile;

$\mathrm{d}_{\mathrm{tb1}, 2}^{*}$ and $\mathrm{d}_{\mathrm{tb} 3,4}^{*}$ - diameters of the main circles in the frontal section for the "nonworking part" of the tooth profile;

$\mathrm{x}_{1}, \mathrm{x}_{2}, \mathrm{x}_{3}$ and $\mathrm{x}_{4}$ - the displacement coefficient of the tool for the respective gear wheels. The value of the displacement coefficient of the wheel with internal teeth is assumed to be the same as the displacement coefficient of the equivalent wheel with external teeth.

In this model of kinematic gears there is no restriction in the choice of instrument parameters and gearing module, which make the epicyclical mechanisms attractive for manufacturing when using a method other than standard one - filament erosion.

uniaxial $2 \mathrm{~K}-\mathrm{H}$ gears with connected wheels with asymmetric profile of the teeth (fig.2).

In this gear model the satellite wheel 2 is in external engagement with central wheel 1 and internal wheel 3. If the gear is driven by the central wheel clockwise, the engagement of wheel 1 and 2 is along the active length of the line $\mathrm{B}_{1}{ }^{*} \mathrm{~B}_{2} *$ with profile angle $\alpha_{\mathrm{w}}{ }_{1-2}$.. At the same time the point of contact of wheels 2-3 is along the engagement line $\mathrm{B}_{2} \mathrm{~B}_{3}$ with profile angle $\alpha_{\mathrm{w} 2-3}$

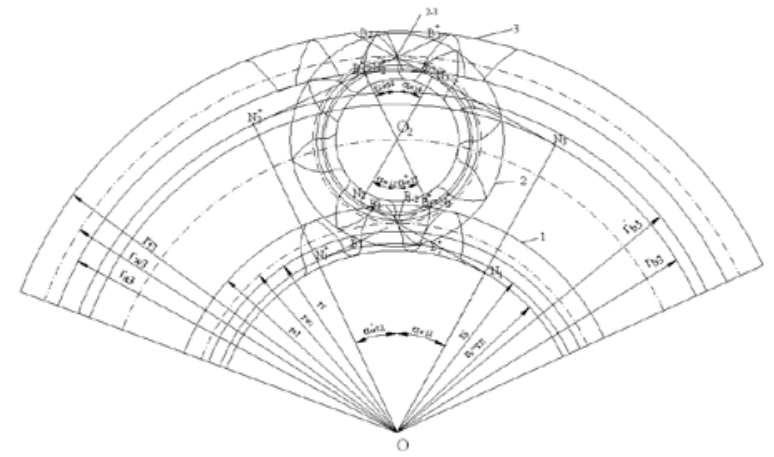

Fig. 2. Computational scheme of planetary gear with asymmetric profile of the teeth

Based on the basic law, the engagement angles for the two parts of the composite profile are determined:

$$
\begin{aligned}
& \operatorname{inv} \alpha_{\mathrm{tw}_{1,2}}+i n v \alpha_{\mathrm{tw}_{1,2}}^{*}=\frac{2 \cdot\left(\mathrm{x}_{2}+\mathrm{x}_{1}\right) \cdot\left(\operatorname{tg} \alpha+\operatorname{tg} \alpha^{*}\right)}{\mathrm{z}_{2}+\mathrm{z}_{1}}+ \\
& +\operatorname{inv} \alpha_{t}+i n v \alpha_{t}^{*} \\
& \frac{\mathrm{d}_{\mathrm{tb}_{1,2}}}{\cos \alpha_{\mathrm{tw}_{1,2}}}=\frac{\mathrm{d}_{\mathrm{tb}_{3,4}}^{*}}{\cos \alpha_{\mathrm{tw}_{1,2}}^{*}} \\
& \operatorname{inv} \alpha_{\mathrm{tw}_{2,3}}+\operatorname{inv} \alpha_{\mathrm{tw}_{2,3}}^{*}=\frac{2 \cdot\left(\mathrm{x}_{3}-\mathrm{x}_{2}\right) \cdot\left(\operatorname{tg} \alpha+\operatorname{tg} \alpha^{*}\right)}{\mathrm{z}_{3}-\mathrm{z}_{2}}+ \\
& +\operatorname{inv}_{\mathrm{t}}+\operatorname{inv}_{\mathrm{t}}^{*} \\
& \frac{\mathrm{d}_{\mathrm{tb}_{2,3}}}{\cos \alpha_{\mathrm{tw}_{2,3}}}=\frac{\mathrm{d}_{\mathrm{tb}_{2,3}}^{*}}{\cos \alpha_{\mathrm{tw}_{2,3}}^{*}}
\end{aligned}
$$

In the case of asymmetric tooth profile it is necessary to take into account the driving unit because it affects the alignment condition [6] [7] [8]. The use of the standard dependency for symmetric profile is possible when the drive is performed by satellite wheel 2 :

$$
\begin{gathered}
\mid \begin{array}{l}
\frac{\cos \alpha_{\mathrm{tw}_{1,2}}}{\cos \alpha_{\mathrm{tw}_{2,3}}}=\frac{\mathrm{z}_{1}+\mathrm{z}_{2}}{\mathrm{z}_{3}-\mathrm{z}_{2}} \\
\frac{\cos \alpha_{\mathrm{tw}_{1,2}}^{*}}{\cos \alpha_{\mathrm{tw}_{2,3}}^{*}}=\frac{\mathrm{z}_{1}+\mathrm{z}_{2}}{\mathrm{z}_{3}-\mathrm{z}_{2}} \\
\frac{\cos \alpha_{\mathrm{tw}_{1,2}}^{*}}{\cos \alpha_{\mathrm{tw}_{2,3}}}=\frac{\mathrm{z}_{1}+\mathrm{z}_{2}}{\mathrm{z}_{3}-\mathrm{z}_{2}} \cdot \frac{\cos \alpha_{\mathrm{t}}^{*}}{\cos \alpha_{\mathrm{t}}} \\
\frac{\cos \alpha_{\mathrm{tw}_{1,2}}}{\cos \alpha_{\mathrm{tw}_{2,3}}^{*}}=\frac{\mathrm{z}_{1}+\mathrm{z}_{2}}{\mathrm{z}_{3}-\mathrm{z}_{2}} \cdot \frac{\cos \alpha_{\mathrm{t}}}{\cos \alpha_{\mathrm{t}}^{*}}
\end{array}
\end{gathered}
$$

The quality indicators of the planetary gears with asymmetric profile depend on the parameters of the tool, its coefficient of displacement and the parameter q:

$$
\mathrm{q}=\mathrm{z}_{3}-\mathrm{z}_{2}-2 . \mathrm{z}_{1}
$$


When selecting the number of teeth of the gear wheels, so that the parameter $\mathrm{q}$ has a value of zero the following correlations for the alignment condition of the gear are obtained:

$$
\mid \begin{aligned}
& \frac{\cos \alpha_{\mathrm{tw}_{1,2}}^{*}}{\cos \alpha_{\mathrm{tw}_{2,3}}}=\frac{\cos \alpha_{t}^{*}}{\cos \alpha_{\mathrm{t}}} \\
& \frac{\cos \alpha_{\mathrm{tw}_{1,2}}}{\cos \alpha_{\mathrm{tw}_{2,3}}^{*}}=\frac{\cos \alpha_{t}}{\cos \alpha_{t}^{*}}
\end{aligned}
$$

After determining the engagement angles for the two parts of the composite profile a method for calculating the vertex circle of the wheel is selected. Irrespective of the adopted method of making the wheels, the following correlation should always be observed:

$$
d_{a 2}^{12}=d_{a 2}^{23}
$$

where $\mathrm{d}^{12}{ }_{\mathrm{a} 2}$ is diameter of the vertex circle for wheel 2, but determined by external meshing with wheel 1 ;

$d_{a 2}^{23}$ - diameter of vertex circle for wheel 2, but determined by internal meshing with wheel 3;

With this method of forming the profile the radial clearance at external and internal meshing is kept constant, and the standard method of checking the qualitative indicators is fully applicable. The checking of the radial clearance ratio is performed only between the heel circle of the wheel with internal teeth and the vertex circle of the satellite $\left(c_{23}\right)$. In the case of a negative value of the coefficient $c_{23}$, a tool for manufacturing the wheel with internal teeth with increased coefficient of the tooth height is selected.

Thus, the proposed approach for making the gear wheels with asymmetric profile has the following advantages:

- the teeth of the gear wheels have different heights at different displacement coefficients;

- the involute profile of the teeth with internal gearing is entirely used, achieving higher values of the frontal overlapping;

- for the wheels with external gearing a tool with standard heights is used;

The asymmetric profile of the teeth makes it possible to obtain an involute cylindrical gear which has a constant gear ratio, but has different quality indicators when reversing the movement direction [9] [10].

One of the quality indicators of particular interest is the coefficient of the pitch point displacement of gearing $\delta$, because the asymmetry and its possibilities of generation make it possible to influence its value. This makes it possible to obtain gears with hitherto unknown quality indicators.
For the case of pitch point displacement $\Sigma$ shown in fig. 3 a) and b), the displacement coefficients $\delta_{1,2}$ and $\delta_{1,2}^{*}$ are determined successively for the two parts of the tooth:

$$
\mid \begin{aligned}
& \delta_{1,2}=\cos \alpha_{\mathrm{t}} \cdot\left[\frac{\mathrm{z}_{1,2} \cdot\left(\operatorname{tg} \alpha_{\mathrm{ta}_{1,2}}-\operatorname{tg} \alpha_{\mathrm{tw}}\right)}{2}-\pi\right] \\
& \delta_{1,2}^{*}=\cos \alpha_{\mathrm{t}}^{*} \cdot\left[\frac{\mathrm{z}_{1,2} \cdot\left(\operatorname{tg} \alpha_{\mathrm{ta}_{1,2}}^{*}-\operatorname{tg} \alpha_{\mathrm{tw}}^{*}\right)}{2}-\pi\right]
\end{aligned}
$$

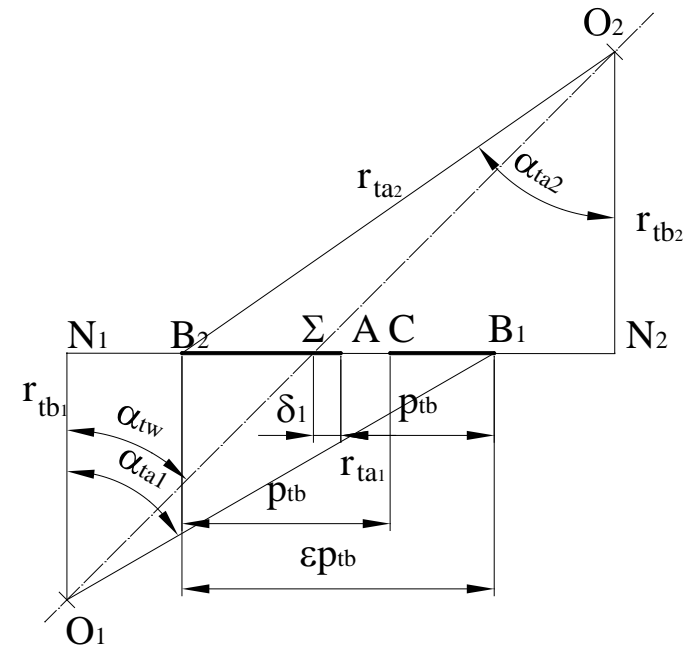

Fig. 3. a) at the base of the tooth of wheel -1 and the head of the tooth of wheel - 2

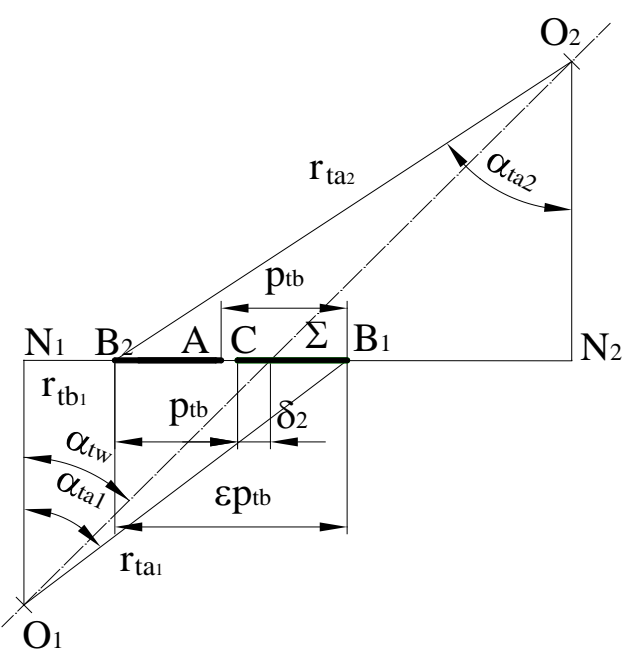

Fig. $3 \mathrm{~b}$ ) at the base of the tooth of wheel -2 and the head of the tooth of wheel -1

The asymmetric tooth profile hasn't been considered in this respect, as well as the effects that can be achieved with it.

From fig 3 a) and b) and from dependency (8) it follows that the asymmetry of the profile leads to obtaining involute cylindrical gears that has “prediction „and “addiction” of the pitch point. 
Therefore the asymmetry of the profile allows:

- $\quad$ to realize gears with different quality indicators when reversing movement direction;

- $\quad$ to achieve different load capacity of the gear wheels with and without revering the direction of movement;

- to design a gear that takes into account the stiffness of the meshing when reversing, and the actual frontal overlapping coefficient of the profiles;

The unconditional existence area makes possible the realization of one gear with preset extreme quality indicators in the field of different independent variables. For the purposes of this work, the following values of the quality indicators are accepted as limiting:

- $\mathrm{S}_{\mathrm{ta} 1,2}^{\Sigma}=\mathrm{S}_{\mathrm{ta} 1,2}=0$ - thickness of the teeth on the vertex circles, determined by the milling method;

- $\varepsilon=1,0$ и $\varepsilon^{*=1,0}$ - frontal overlapping coefficients when reversing movement direction;

- $\left|\theta_{\mathrm{a}}\right|=6,0 ;\left|\theta_{\mathrm{a}}\right|=6,0 ;\left|\theta_{\mathrm{e}}\right|=6,0 ;\left|\theta_{\mathrm{e}}\right|=6,0$ - coefficient of specific sliding between the profiles;

- $\quad \mathrm{c}=0$ - radial clearance between the wheel and the gear;

The conditional area of existence determines a certain limit for the quality indicators, but only above a certain extreme value. Therefore, the unconditional area of existence contains in itself a number of conditional areas, offering the possibilities for realization of such gears.

In such a synthesis approach the displacement coefficient of the internal gear wheel $\left(\mathrm{x}_{3}\right)$ is obtained as a dependent variable:

$$
x_{3}=x_{2}+\frac{\left(i n v \alpha_{t w 23}+i n v \alpha_{t w 23}^{*}-i n v \alpha_{t}-i n v \alpha_{t}^{*}\right)\left(z_{3}-z_{2}\right)}{2 \cdot\left(\operatorname{tg} \alpha+\operatorname{tg} \alpha^{*}\right)}
$$

To illustrate the unconditional areas of existence, consider a $2 \mathrm{~K}-\mathrm{H}$ planetary gear with parameters: $\mathrm{m}=1 \mathrm{~mm}$, $\alpha=20^{\circ}, \alpha^{*}=30^{\circ}, h^{*}{ }_{a}=1, h^{*}{ }_{\mathrm{f}}=1.25$, number of teeth of the gear wheels $-z_{1}=30, z_{2}=20, z_{3}=70$, angle of inclination of the teeth $\beta=0$ and open profile milling method, with and without reversing the direction of movement.

The geometric interpretation of contour lines with constant magnitude of the coefficient $\mathrm{x}_{3}$ is inclined straights relative to the displacement coefficients $x_{1}$ and $x_{2}$ (fig. 4 and 5). The contour lines of constant coefficient $\mathrm{x}_{3}$ coincide with contour lines of coefficient $\mathrm{x}_{1}$ only in the case of symmetric profile.

The slope of the contour lines (isolines) $\mathrm{x}_{3}$ is determined by the set asymmetry between the composite profiles. This allows the cross section of the spatial area of existence to be considered as a plane, where $\mathrm{x}_{3}=\mathrm{x}_{1}$ is satisfied along the ordinate of the unconditional area.

Fig 4 and 5 show the unconditional areas of existence of planetary gear depending on the drive mechanism. They are valid when involute corresponding to profile angle $\alpha_{t}$ is selected for working angle of the gear with external gearing.

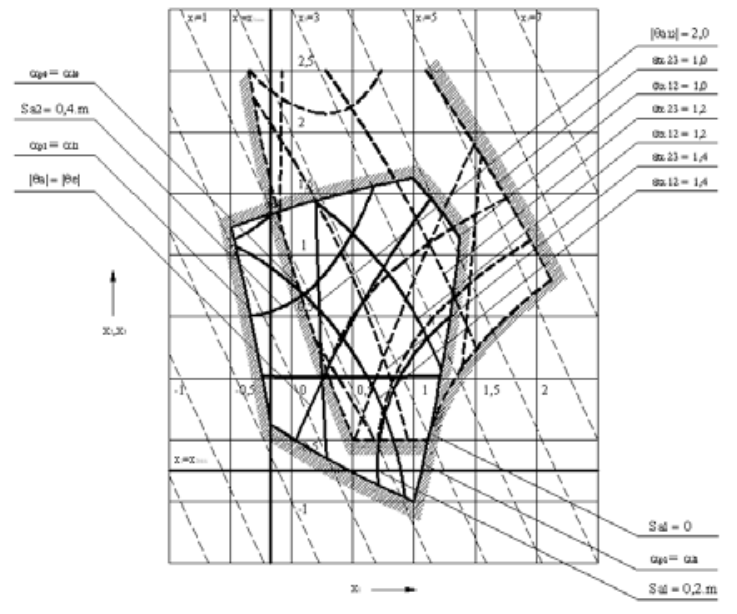

Fig. 4. Unconditional area of existence of a planetary gear with asymmetric profile of the teeth, driven by wheel 1 or 3

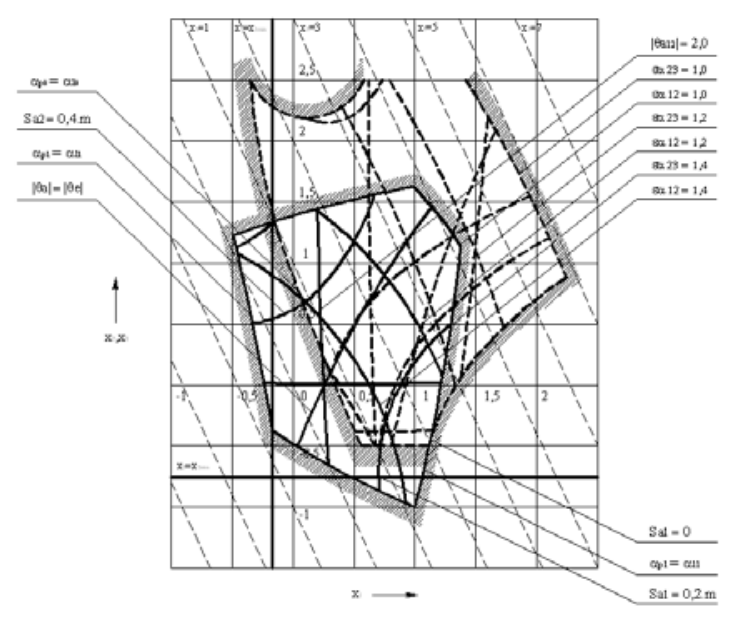

Fig. 5. Unconditional area of existence of a planetary gear with asymmetric tooth profile driven by satellite wheel 2

When reversing the direction of motion of the planetary mechanism, the areas of existence have another axiomatic form.

If we adopt the concept of "complex" unconditional area of existence in planetary gears with asymmetric tooth profile, we find that there are two such areas which depend on the driving mechanism. The two complex areas are a consistent combination of the qualitative indicators of engagement with and without reversing of the direction of movement.

Fig.6 shows a spatial solid model of $2 \mathrm{~K}-\mathrm{H}$ gear designed by CAD/CAM system of company "AutodeskInventor Professional” 
Based on the presented geometric synthesis of planetary involute cylindrical gears with asymmetric tooth profile, it is possible to achieve large gear ratios. This is possible by reducing the number of teeth of the satellite wheel and selecting an appropriate asymmetry and drive of the gear mechanism.

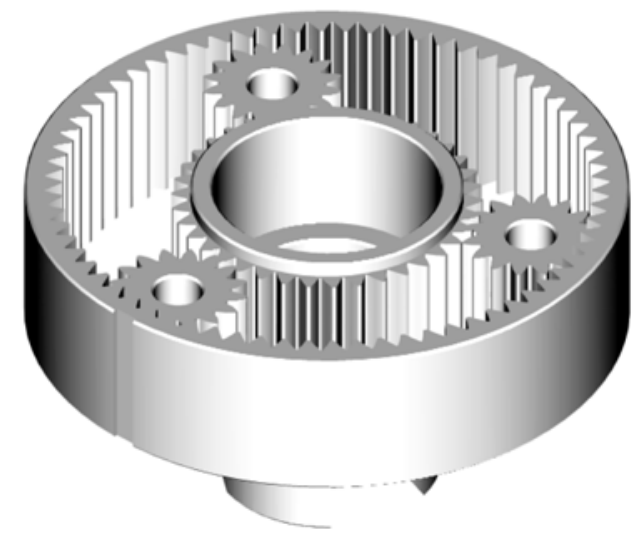

Fig. 6. Solid model of $2 \mathrm{~K}-\mathrm{H}$ gear with asymmetric tooth profile and geometrically connected gear wheels

\section{CONCLUSION}

The traditional approach in geometric synthesis of $2 \mathrm{~K}$ $\mathrm{H}$ gears with asymmetric tooth profile with and without connected gear wheels and combined gearing in different possibilities of generation is presented. Also presented is the necessary condition for alignment.

The main qualitative indicators are given and the pitch point displacement is defined for the different possibilities of generation, which allows the creation of sub-polar and post-polar gears with increased efficiency because these gears are used in measuring devices.

A field of the independent displacement coefficients of the initial contour is defined, which allows the spatial unconditional areas of existence of the $2 \mathrm{~K}-\mathrm{H}$ gear to be depicted as a plane.

\section{REFERENCES}

[1] E. B. Vulgakov, Teoriya evolyventayh zubchatayh peredach, Moskva: Mashinostroenie, 1995.

[2] E. B. Vulgakov, Soosnaye zubchataye peredachi. Spravochnik, Moskva: Mashinostroenie, 1987.

[3] Spravochnik po geometricheskomu raschetu evolyventayh zubchatayh i chervyachnayh peredach, I. A. Bolotovskogo ed., Moskva: Mashinostroenie, 1986.

[4] S. Simeonov and G. Tsvetanov, "Theorem for reversing the direction of the involute cylindrical gears with asymmetric profile of teeth," Mechanics of machines, no. 63, 2005, ISSN 0861-9727

[5] S. Simeonov and G. Tsvetanov, "Theorem for reversing the direction of the involute cylindrical gears with asymmetric profile of teeth," Proceedings of the Technical University of Gabrovo, no. 32, 2005, ISSN 1310-6686

[6] D. Dichev, H. Koev, T. Bakalova and P. Louda, "A model of the dynamic error as a measurement result of instruments defining the parameters of moving objects," Measurement Science Review, vol. 14, no. 4, pp. 183-189, 2014, DOI: 10.2478/msr-2014-0025

[7] D. Dichev, H. Koev, T. Bakalova and P. Louda, "An algorithm for improving the accuracy of systems measuring parameters of moving objects," Metrology and Measurement Systems, vol. 23, no. 4, pp. 555-565, 2016, DOI: 10.1515/mms-2016-0041

[8] L. Lazov, E. Teirumnieks, N. Angelov and E. Teirumnieka, "Methodology for Automatic Determination of Contrast of Laser Marking for Different Materials," in Proceedings of the 12th International Scientific and Practical Conference, Rezekne Latvia, 2019, DOI: 10.17770/etr2019vol3.4143

[9] X. Zhao and A. Vacca, "Formulation and optimization of involute spur gear in external gear pump," Mechanism and Machine Theory, vol. 117, pp. 114-132, November 2017, DOI: 10.1016/j.mechmachtheory.2017.06.020

[10] C. G. Conev and K. S. Davidov, "Analytical Model For Approximately Calculating Of The Second Frequency Of Cross Vibrations For Complex Shape Barrel Of The Small ARM," in The 21st International Conference The Knowledge - Based Organization, Sibiu Romania, 2015, ISSN 1843-6722 